\title{
MicroRNA-223 attenuates LPS-induced inflammation in an acute lung injury model via the NLRP3 inflammasome and TLR4/NF-кB signaling pathway via RHOB
}

\author{
YURONG YAN ${ }^{1,2}$, KEXIN LU $^{3}$, TING YE ${ }^{2}$ and ZONGWANG ZHANG ${ }^{4}$ \\ ${ }^{1}$ Shandong University, Jinan, Shandong 250012; Departments of ${ }^{2}$ Anesthesiology and ${ }^{3}$ Obstetrics, \\ Binzhou Medical University Hospital, Binzhou, Shandong 256600; ${ }^{4}$ Department of Anesthesiology, \\ Liaocheng People's Hospital, Liaocheng, Shandong 252000, P.R. China \\ Received February 17, 2018; Accepted January 17, 2019
}

DOI: $10.3892 /$ ijmm.2019.4075

\begin{abstract}
Acute lung injury (ALI) and the more severe acute respiratory distress syndrome are common and complex inflammatory lung diseases. MicroRNAs (miRs) have emerged as novel gene regulatory molecules, serving a crucial role in a variety of complex diseases, including ALI. In the present study, the anti-inflammatory action of miR-223 on inflammation in ALI was demonstrated and the possible mechanism was further examined. In lipopolysaccharide-induced ALI, the expression of miR-223 was reduced compared with that in the control normal group. An in vitro model was used to analyze the effect of miR-223 downregulation on an ALI model, which increased inflammation, and induced the activation of the NACHT, LRR and PYD domains-containing protein 3 (NLRP3) inflammasome and Toll-like receptor 4 (TLR4)/nuclear factor (NF)- $\mathrm{BB}$ signaling pathway via rho-related GTP-binding protein $\mathrm{RhoB}$ (RHOB). In addition, the overexpression of miR-223 reduced inflammation and suppressed the NLRP3 inflammasome and TLR4/NF- $\kappa B$ signaling pathway via RHOB in the in vitro model. Furthermore, TLR4 inhibitor or NLRP3 inhibitor reduced the pro-inflammatory effect of miR-223 downregulation in ALI. In conclusion, the results of the present study indicated that miR-223 functioned as a biological indicator by regulating inflammation in ALI, and may represent a novel potential therapeutic target and prognostic marker of ALI.
\end{abstract}

Correspondence to: Professor Zongwang Zhang, Department of Anesthesiology, Liaocheng People's Hospital, 67 Dongchangfu West Road, Dongchangfu, Liaocheng, Shandong 252000, P.R. China E-mail: vy281369@163.com

Key words: microRNA-223, acute lung injury, inflammation, NACHT, LRR and PYD domains-containing protein 3, Toll-like receptor 4, rho-related GTP-binding protein $\mathrm{RhoB}$

\section{Introduction}

Acute lung injury (ALI)/acute respiratory distress syndrome (ARDS) refers to the acute progressive respiratory insufficiency or respiratory failure caused by various factors, including trauma, blood transfusion and infection (1); this is a common respiratory crisis, pathologically characterized by pulmonary edema, pulmonary hemorrhage and severe respiratory impairment (1). The mortality rate of ALI/ARDS may be as high as $30-50 \%$ (2). Due to the undefined pathogenesis, there are no effective therapeutic drugs in clinical practice at present (2). Supportive treatment remains the principal treatment option (3). A series of ALI animal models have been established to simulate the status of ALI caused by diverse pathogeneses (3). Among them, the majority of studies have focused on lipopolysaccharide (LPS), one of the primary causative factors of ALI caused by bacterial infections, particularly Gram-negative bacteria (3). As the active component of bacterial endotoxin, LPS is an important pathogenic factor in ALI (4). In LPS-induced ALI animal models, the excessive inflammatory reaction of neutrophils leads to extensive damage and even mortality (4).

The NACHT, LRR and PYD domains-containing protein 3 (NLRP3) inflammasome is a multiprotein large-cytoplasmic complex, which is composed of NLRP3, apoptosis-associated speck-like proteins and pro-caspase-1 (5). NLRP3 serves a critical role in regulating the relevant components of the inflammatory complex, including apoptosis-associated speck-like proteins and pro-caspase-1 (6). It has been reported that in acute injury, the stimulated intracellular reactive oxygen species may activate the NLRP3 inflammasome and caspase-1, and promote the cleavage and maturation of pro-interleukin (IL)- $1 \beta$ and pro-IL-18. As a result, inflammatory cytokines are released, resulting in damage to lung tissue $(7,8)$.

Alterations in microRNA (miRNA/miR) expression are associated with immune responses, inflammatory signaling pathways and the pathogenesis of inflammatory lung diseases, including ALI. Therefore, miRNAs are novel promising therapeutic targets (9). miRNA-induced changes in gene expressions are generally modest (9). However, the results may affect the expression of a large number of subsequent genes, which 
further affect multiple biological processes. Therefore, it is feasible to utilize miRNAs as markers (10). miRNA expression has been verified to be dynamic, which reflects alterations in the internal and external environments, and cell signals (10). Therefore, it is promising to use miRNAs as biomarkers to represent a specific disease state or the underlying pathophysiological processes at different stages. In addition, miRNAs may be detected in a variety of specimens, including tissue, blood or other body fluids (11). miRNAs are also fairly stable and are virtually unaffected by errors in sample handling, making miRNAs more attractive biomarkers (11). Intriguingly, miRNAs in plasma have been used as biomarkers to diagnose and monitor a variety of inflammatory lung diseases, including ALI. Neudecker et al (12) suggested that miRNA-223 deficiency was associated with severe lung inflammation. In the present study, the anti-inflammatory effect of miRNA-223 on inflammation in ALI, and the possible mechanism, was demonstrated.

\section{Materials and methods}

Mice and histopathological assay. Male C57BL/6 mice (5-6 weeks; 18-20 g) were obtained from Shandong University Laboratory Animal Center (Jinan, China). All mice were housed at $22-23^{\circ} \mathrm{C}, 55-60 \%$ humidity, on a 12 -h light/dark cycle with free access to food/water. All mice were randomly assigned to two groups: Control and ALI mice. All ALI model mice were injected with $35 \mathrm{mg} / \mathrm{kg}$ pentobarbital sodium [intraperitoneal (i.p.)] and injected with LPS at $5 \mathrm{mg} / \mathrm{kg}$ (Sigma-Aldrich; Merck KGaA, Darmstadt, Germany) into the chest. After 1 day, all mice were injected with $35 \mathrm{mg} / \mathrm{kg}$ pentobarbital sodium and sacrificed via decollation. Lung tissue was acquired and washed with PBS, and fixed with $4 \%$ paraformaldehyde for $24 \mathrm{~h}$ at room temperature. The lung tissue was dehydrated using 100-75\% ethyl alcohol for $5 \mathrm{~min}$ at $4^{\circ} \mathrm{C}$, and cut into $5-\mu \mathrm{M}$ sections. Lung tissue sections were stained with hematoxylin and eosin (HE) for $5 \mathrm{~min}$ at room temperature, and were finally examined under a light microscope (Nikon Eclipse TE2000-U; Nikon Corporation, Tokyo, Japan) at x100 magnification. The experimental procedures in the present study were performed with the approval of Binzhou Medical University Hospital (Liaocheng, China).

Cytokine detection. Serum samples were centrifuged at $1,000 \mathrm{x} \mathrm{g}$ for $10 \mathrm{~min}$ and used to measure TNF- $\alpha$ (cat. no. H052), IL-1 $\beta$ (cat. no. H002), IL-6 (cat. no. H007) and IL-18 (cat. no. H0015) levels using ELISA kits (Nanjing Jiancheng Bioengineering Institute, Nanjing, China). Cells were lysed with radioimmunoprecipitation assay buffer for $15 \mathrm{~min}$ and protein concentrations in the extracts were measured by bicinchoninic acid assay. Proteins $(10 \mu \mathrm{g})$ were centrifuged at $1,000 \mathrm{x} g$ for $10 \mathrm{~min}$ and collected to measure TNF- $\alpha$, IL-1 $\beta$, IL-6 and IL-18 levels using ELISA kits.

Measurement of miRNA and mRNA expression. Total RNA was extracted from lung tissues or cells using TRIzol reagent, according to the manufacturer's instructions (Invitrogen; Thermo Fisher Scientific, Inc., Waltham, MA, USA). cDNA was synthesized using a qScript cDNA Synthesis kit (QuantaBio, Beverly, MA, USA) at $37^{\circ} \mathrm{C}$ for $60 \mathrm{~min}$ and at $82^{\circ} \mathrm{C}$ for $5 \mathrm{sec}$. Reverse transcription-quantitative polymerase chain reaction (RT-qPCR) analysis was executed using a SYBR Green Detection system (Bio-Rad Laboratories, Inc., Hercules, CA, USA) on a 7500 real-time PCR systems (Applied Biosystems; Thermo Fisher Scientific, Inc.). Primer sequences were as follows: miR-223 forward, 5'-GTGCAGGGTCCG AGGT-3' and reverse, 5'-CGGGCTGTCAGTTTGTCA-3'; U6 forward, 5'GCTTCGGCAGCACATATACTAAAAT3' and reverse, 5'CGCTTCACGAATTTGCGTGTCAT3. The PCR conditions were $95^{\circ} \mathrm{C}$ for $30 \mathrm{sec}$, followed by 40 cycles of $95^{\circ} \mathrm{C}$ for $20 \mathrm{sec}, 60^{\circ} \mathrm{C}$ for $30 \mathrm{sec}$ and $72^{\circ} \mathrm{C}$ for $30 \mathrm{sec}$. Analysis of relative gene expression data was performed using the $2^{-\Delta \Delta \mathrm{Cq}}$ method (13).

Microarray analysis. Isolated RNA was cleaned up using an RNeasy Mini kit (Qiagen, Inc., Valencia, CA, USA) and biotin-labeled cRNA was produced by metal-induced hydrolysis at $94^{\circ} \mathrm{C}$ and hybridized onto the Affymetrix Human Genome U133 Plus 2.0 Array (Affymetrix; Thermo Fisher Scientific, Inc.) at $45^{\circ} \mathrm{C}$ for $16 \mathrm{~h}$. Fluidic Station-450 and GeneChip were performed using the Affymetrix GeneChip Scanner 7G (Affymetrix; Thermo Fisher Scientific, Inc.). Data were analyzed using GeneSpring GX 10 software (Silicon Genetics; Agilent Technologies, Inc., Santa Clara, CA, USA).

Cell culture and transfection. Lung adenocarcinoma A549 cells were obtained from the Shanghai Cell Bank of the Chinese Academy of Sciences (Shanghai, China), and maintained in Dulbecco's modified Eagle's medium (high glucose; Invitrogen; Thermo Fisher Scientific, Inc.) supplemented with $10 \%$ fetal bovine serum (Gibco; Thermo Fisher Scientific, Inc.). A549 cells were treated with $100 \mathrm{ng}$ LPS and $2 \mathrm{mM}$ adenosine 5'-triphosphate (ATP) for $4 \mathrm{~h}$ for the ALI model. miRNA-223, anti-miRNA-223, RHOB plasmid and negative mimics were purchased from Sangon Biotech Co., Ltd. (Shanghai, China). A549 cells $\left(1 \times 10^{6}\right.$ cells/ml) were co-transfected with $0.1 \mu \mathrm{g}$ miRNA-223 (5'-UGUCAGUUUGUCAAA UACCCCA-3'), anti-miRNA-223 (5'-TGTCAGTTTGTCAAA TACCCCAT-3'), RHOB plasmid (5'-CGCTCATGGAGG CCATCCGC-3' and 5'-CTGCAATGCTATGAGGGC-3'; Sangon Biotech Co., Ltd.) and negative mimics (5'-AGGUCG AACUACGGGUCAAUC-3') using Lipofectamine ${ }^{\circledR} 2000$ (Invitrogen; Thermo Fisher Scientific, Inc.). After 6 h, transfected cells were treated with 100 ng LPS (Sigma-Aldrich; Merck KGaA, Darmstadt, Germany) and $2 \mathrm{mM}$ ATP (Sigma-Aldrich; Merck KGaA, Darmstadt, Germany) for $4 \mathrm{~h}$ for the ALI model.

Luciferase reporter gene assay. TargetScan (http://www. targetscan.org/vert_61/), online bioinformatics software, concluded that NLRP3 is a downstream target gene of miR-223. A549 cells were co-transfected with miRNA-223, anti-miRNA-223, pMIR-REPORT-RhoB-3'-untranslated region (UTR) luciferase reporter plasmid (Huayueyang Biotechnology Co., Ltd., Beijing, China) and pMIR-REPORTNLRP3-3'-UTR (Huayueyang Biotechnology Co., Ltd.) luciferase reporter plasmid using Lipofectamine 2000. A total of $24 \mathrm{~h}$ after transfection, cells were treated with $100 \mathrm{ng}$ LPS and $2 \mathrm{mM}$ ATP for $4 \mathrm{~h}$, and luciferase activity was measured using the Dual-luciferase reporter assay kit (Promega 


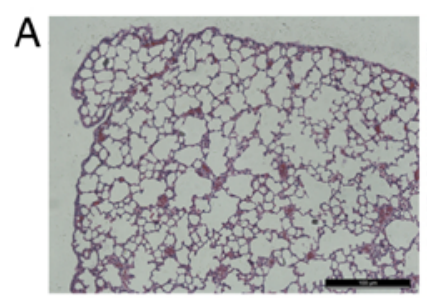

Control
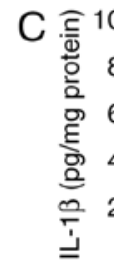

(20)
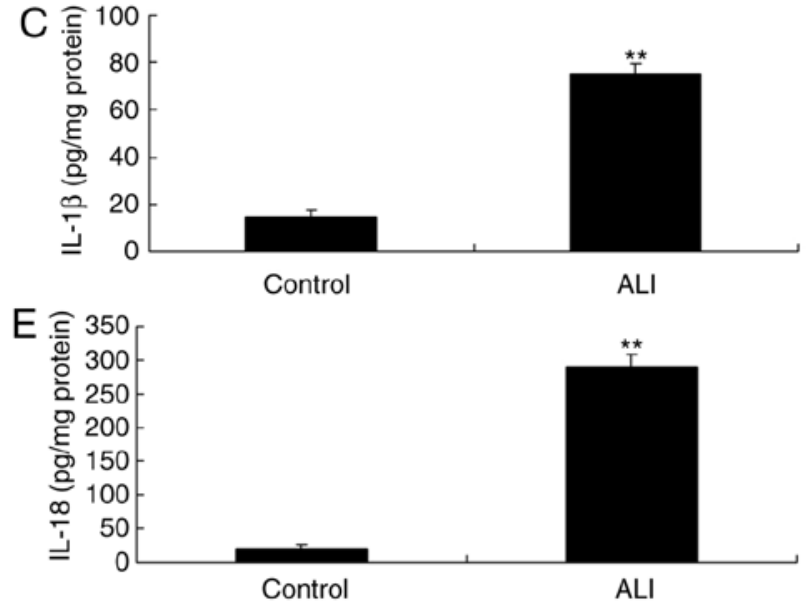

Control

ALI
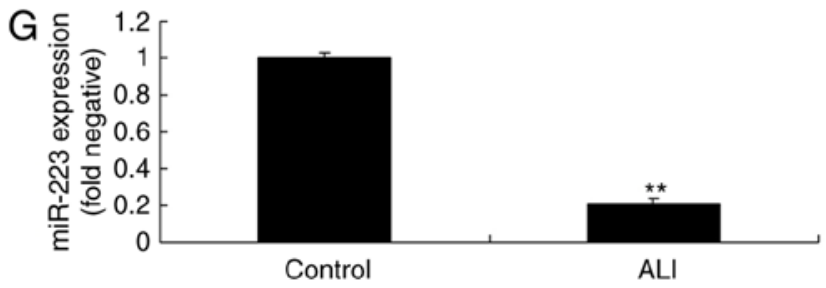
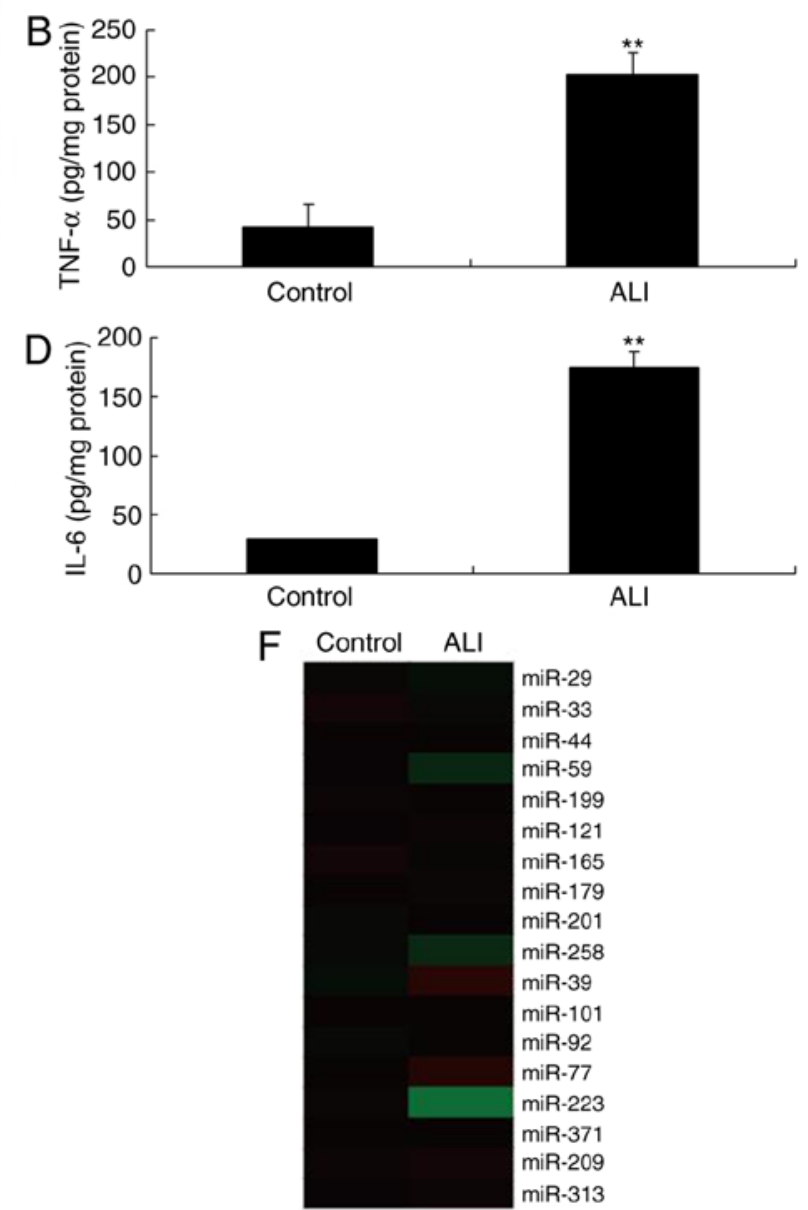

Figure 1. miR-223 expression in ALI mice. (A) Hematoxylin and eosin staining of lung tissue. (B) TNF- $\alpha$, (C) IL-1 $\beta$, (D) IL-6 and (E) IL-18 were assayed. (F) Gene chip and $(\mathrm{G})$ reverse transcription-quantitative polymerase chain reaction analysis for miR-223 expression in $\mathrm{ALI}$ mice. Scale bar, $100 \mu \mathrm{m} .{ }^{* *} \mathrm{P}<0.01$ vs. control. ALI, acute lung injury; miR, microRNA; IL, interleukin; TNF- $\alpha$, tumor necrosis factor- $\alpha$.

Corporation, Madison, WI, USA) in comparison with Renilla luciferase.

Western blot analysis. Cells were lysed with radioimmunoprecipitation assay buffer for $15 \mathrm{~min}$ and protein concentrations in the extracts were measured by bicinchoninic acid assay. Proteins $(50 \mu \mathrm{g})$ were separated by electrophoresis on $10 \%$ SDS-polyacrylamide gels and $3 \%$ polyacrylamide gels and transferred onto nitrocellulose membranes. Membranes were blocked with $5 \%$ bovine serum albumin (BSA; Beyotime Institute of Biotechnology, Haimen, China) in TBS at $37^{\circ} \mathrm{C}$ for $1 \mathrm{~h}$ and incubated with the indicated antibodies: Toll-like receptor 4 (TLR4; 1:2,000; cat. no. ab13556; Abcam, Cambridge, UK), nuclear factor (NF)- $\mathrm{B}(1: 2,000$; cat. no. 8242; Cell Signaling Technology, Inc., Danvers, MA, USA), NLRP3 (1:2,000; cat. no. 13158; Cell Signaling Technology, Inc.), caspase-1 (1:1,000; cat. no. 3866; Cell Signaling Technology, Inc.), RHOB (1:2,000; cat. no. 2098; Cell Signaling Technology, Inc.) and GAPDH (1:5,000; cat. no. 5174; Cell Signaling Technology, Inc.) overnight at $4^{\circ} \mathrm{C}$. Following three washes with TBS with Tween-20 (TBST) for $15 \mathrm{~min}$, the membranes were incubated with anti-rabbit horseradish peroxidase-coupled secondary antibodies (cat. no. 7074; 1:5,000; Cell Signaling Technology, Inc.) at room temperature for $1 \mathrm{~h}$. The membrane was washed with TBST and detected by enhance chemiluminescence (Pierce; Thermo Fisher Scientific, Inc.), and quantified using Image Lab 3.0 (Bio-Rad Laboratories, Inc., Hercules, CA, USA).

Immunofluorescence staining. Cells $\left(1 \times 10^{5}\right.$ cells $\left./ \mathrm{ml}\right)$ were washed with PBS and fixed with $4 \%$ paraformaldehyde in PBS for $15 \mathrm{~min}$ at room temperature. Cells were permeabilized with $0.1 \%$ Triton X-100 in PBS for $15 \mathrm{~min}$ at room temperature and blocked with 5\% BSA in PBS for $1 \mathrm{~h}$. Subsequently, the cells were incubated with anti-RHOB (1:100; cat. no. 2098; Cell Signaling Technology, Inc.) overnight at $4^{\circ} \mathrm{C}$. The cells were washed with PBS, and incubated with goat anti-rabbit IgG-CFL 555 secondary antibodies (cat. no. sc-362272; 1:100; Santa Cruz Biotechnology, Inc., Dallas, TX, USA) for $1 \mathrm{~h}$ at room temperature. Cells were stained with DAPI for $15 \mathrm{~min}$ in the dark at room temperature and washed with PBS. Cells were examined under a Zeiss LSM 510 confocal microscope (Carl Zeiss AG, Oberkochen, Germany).

Statistical analysis. All the experiments were performed at least three times independently $(n=3)$ using SPSS 17.0 (SPSS, Inc., Chicago, IL, USA). A Student's t-test was used to determine statistical significance between two groups. One-way 

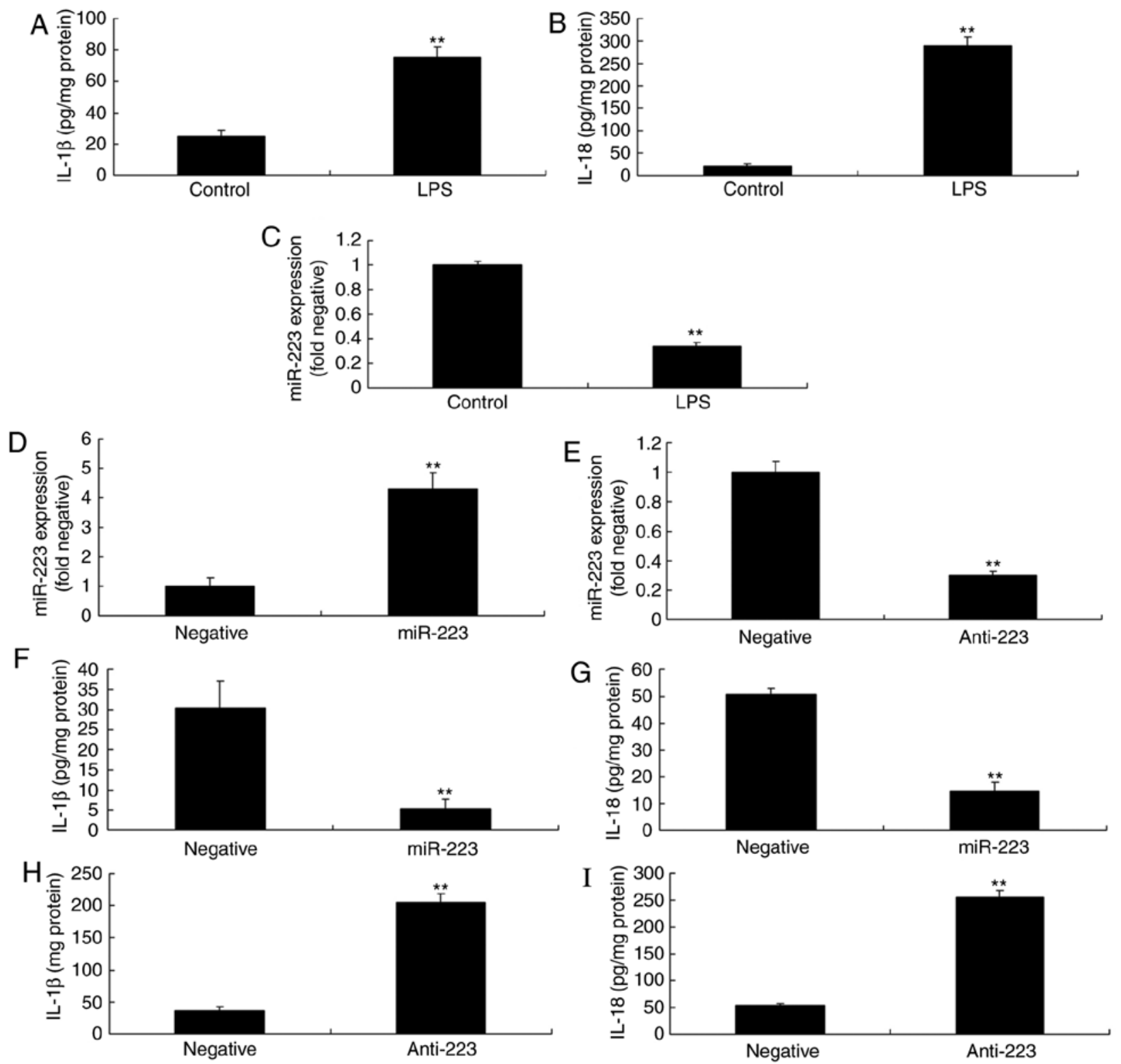

Figure 2. miR-223 expression in ALI in vitro. (A) IL-1 $\beta$, (B) IL-18, (C) miR-223 expression was assessed in vitro in the ALI model induced by LPS. miR-223 expression in cells transfected with (D) miR-233 and (E) anti-miR-223. IL-1 $\beta$ expression in cells transfected with (F) miR-233 and (H) anti-miR-223. IL-18 expression in cells transfected with (G) miR-233 and (I) anti-miR-223. ${ }^{* *} \mathrm{P}<0.01$ vs. respective control. ALI, acute lung injury; miR, microRNA; LPS, lipopolysaccharide; IL, interleukin.

analysis of variance and Tukey's post hoc test were performed for parametric multivariable analysis. $\mathrm{P}<0.05$ was considered to indicate a statistically significant difference.

\section{Results}

miRNA-223 expression in ALI mice. To investigate the function of miR-223 in ALI mice, the alterations in miR-223 was analyzed in ALI mice. As presented in Fig. 1A, HE staining indicated that pulmonary alveoli were damaged in ALI mice compared with control mice. The levels of TNF- $\alpha$, IL-1 $\beta$, IL-6 and IL-18 were increased in ALI mice, in comparison with the control group (Fig. 1B-E). A gene chip assay was used to analyze the alterations in miRNAs, which revealed that miR-223 expression was decreased in ALI mice compared with the control group (Fig. 1F). The RT-qPCR assay demonstrated that miR-223 expression was decreased in ALI mice compared with the control group (Fig. 1G). Therefore, miR-223 expression may be associated with inflammation in ALI.

miR-223 expression in ALI in vitro. Moreover, the levels of IL-1 $\beta$ and IL-18 were increased in A549 cells following treatment with LPS, compared with the control group (Fig. 2A and B). miR-223 expression was reduced in A549 cells following treatment with LPS, compared with the control group (Fig. 2C). To analyze the function of miR-223 in ALI, miR-223 and anti-miR-223 mimics were used to increase or inhibit the expression of miR-223 in A549 cells treated with LPS, compared with a negative control group (Fig. 2D and E). Overexpression of miR-223 reduced the levels of IL-1 $\beta$ and IL-18 in A549 cells following treatment with LPS, compared with the negative control group (Fig. 2F and G). 
A Negative Anti-223
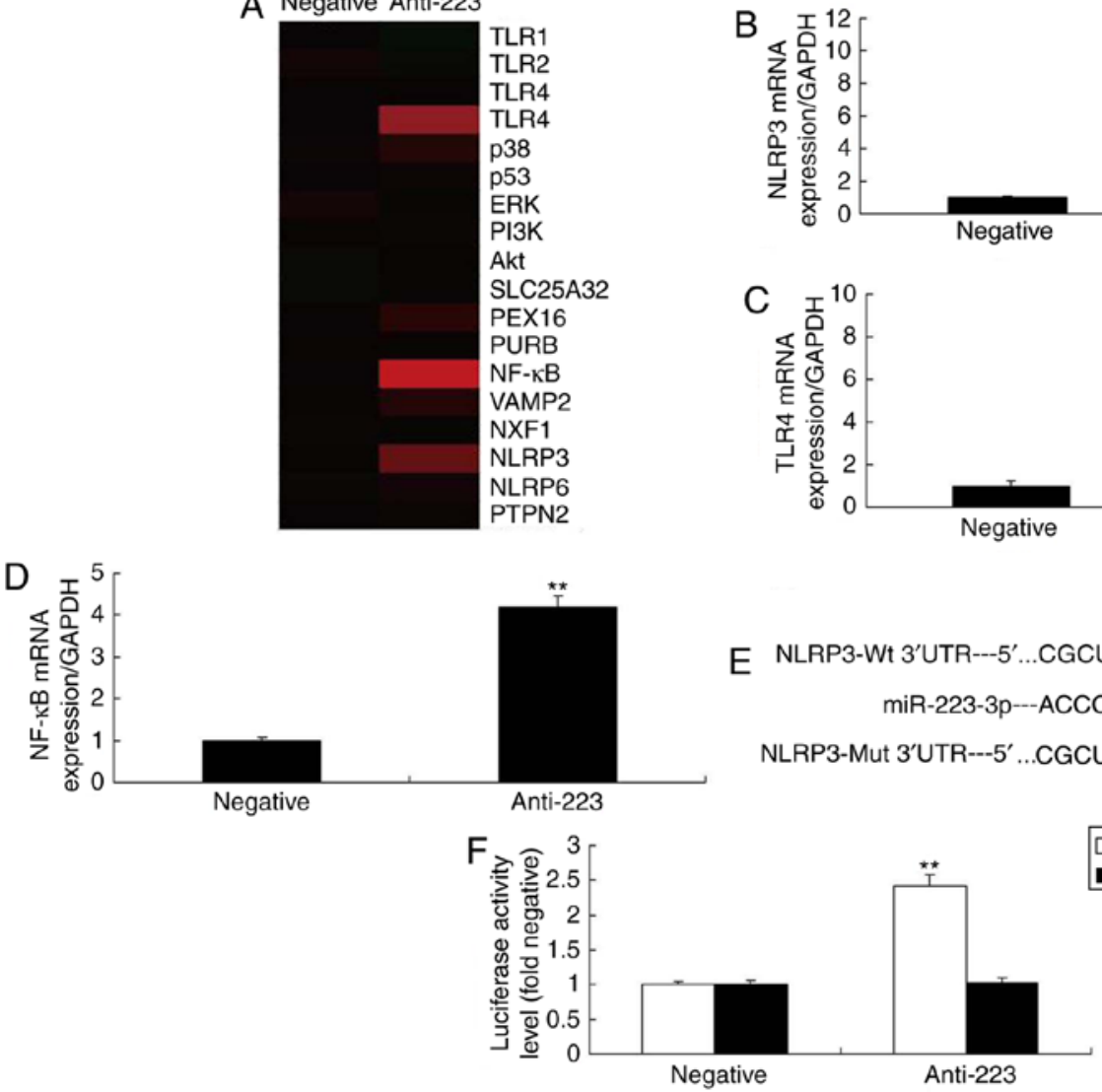

G

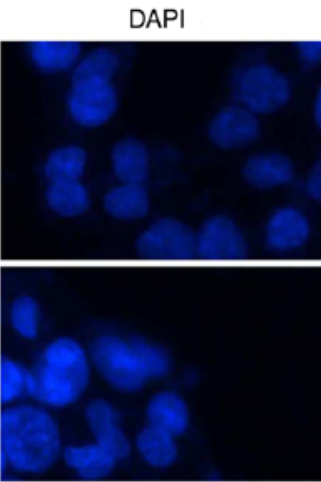

NLRP3

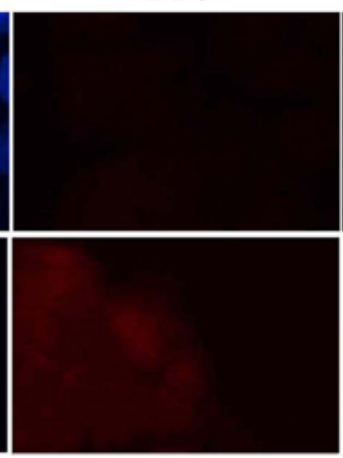

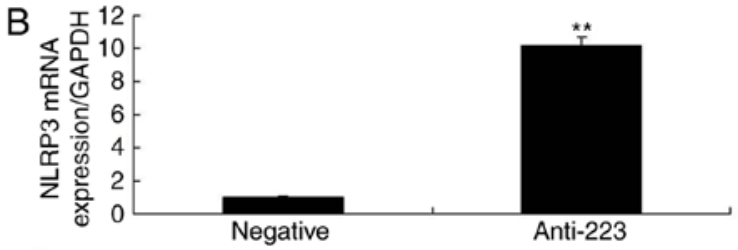

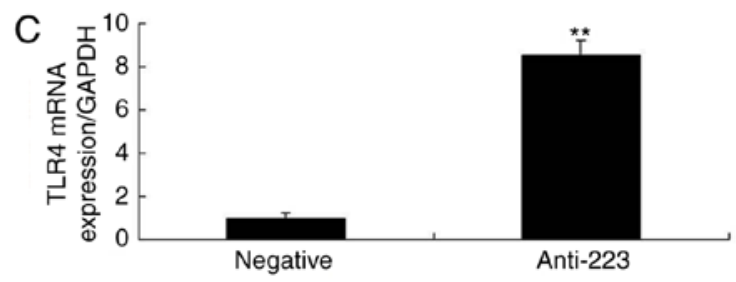

E NLRP3-Wt 3'UTR---5'...CGCUAUCUUUCUAUUAACUGACC... miR-223-3p--ACCCCAUAAACUGU--UÚGACUGU NLRP3-Mut 3'UTR---5' ...CGCUAUCUUUUCUAUUGÁUAACC...

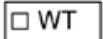

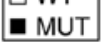

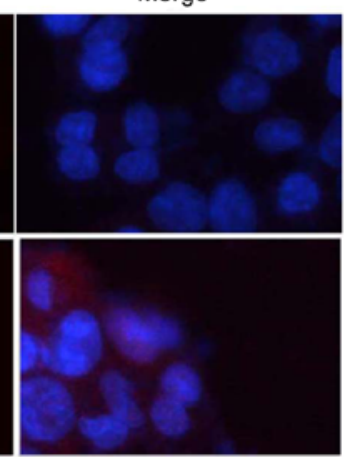

Control

Anti-223

Figure 3. miR-223 regulates NLRP3 protein expression in acute lung injury in vitro. (A) Gene chip assay of the signaling pathway. (B) NLRP3, (C) TLR4 and (D) NF- $\kappa$ B mRNA expression. (E) Predicted miR-223 binding sites in the NLRP3 3'-UTR. (F) Dual-luciferase reporter gene assay. (G) Immunofluorescence for NLRP3 protein expression. Magnification, $\mathrm{x} 200{ }^{*}{ }^{* *} \mathrm{P}<0.01$ vs. respective control. UTR, untranslated region; NLRP3, NACHT, LRR and PYD domains-con-

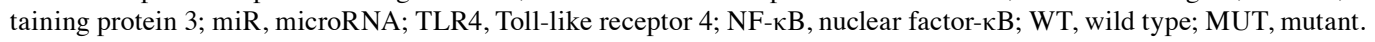

Downregulation of miR-223 promoted the levels of IL-1 $\beta$ and IL-18 in A549 cells treated with LPS, compared with the negative control group (Fig. $2 \mathrm{H}$ and I). Together, these results demonstrated that miR-223 regulated inflammation in ALI, while its mechanism required investigation.

miRNA-223 regulates NLRP3 protein expression in ALI in vitro. In order to investigate the mechanism of action of miR-223 in ALI, a gene chip assay was used to measure the alterations in miR-223 in ALI in vitro following inhibition of miR-223. Consequently, inhibition of miR-223 induced the gene expression of TLR4, NF- $\kappa \mathrm{B}$ and NLRP3 in ALI in vitro compared with the negative control (Fig. 3A). Downregulation of miR-223 also increased the mRNA expression of TLR4,
$\mathrm{NF}-\kappa \mathrm{B}$ and NLRP3 in ALI in vitro, compared with the negative control group (Fig. 3B-D). The 3'-UTR of NLRP3 mRNA is a target site of miR-223 in various species (Fig. 3E). The relative luciferase activity of the wild-type 3'-UTR following downregulation of miR-223 was increased, in comparison with the control group (Fig. 3F). As presented in Fig. 3G, immunofluorescence demonstrated that the downregulation of miR-223 induced NLRP3 protein expression compared with the control group. These results indicated that miR-223 may regulate pro-inflammatory cytokine expression by targeting NLRP3.

miRNA-223 regulates the TLR4 and NLRP3 signaling pathway in ALI in vitro. Downregulation of miR-223 induced 

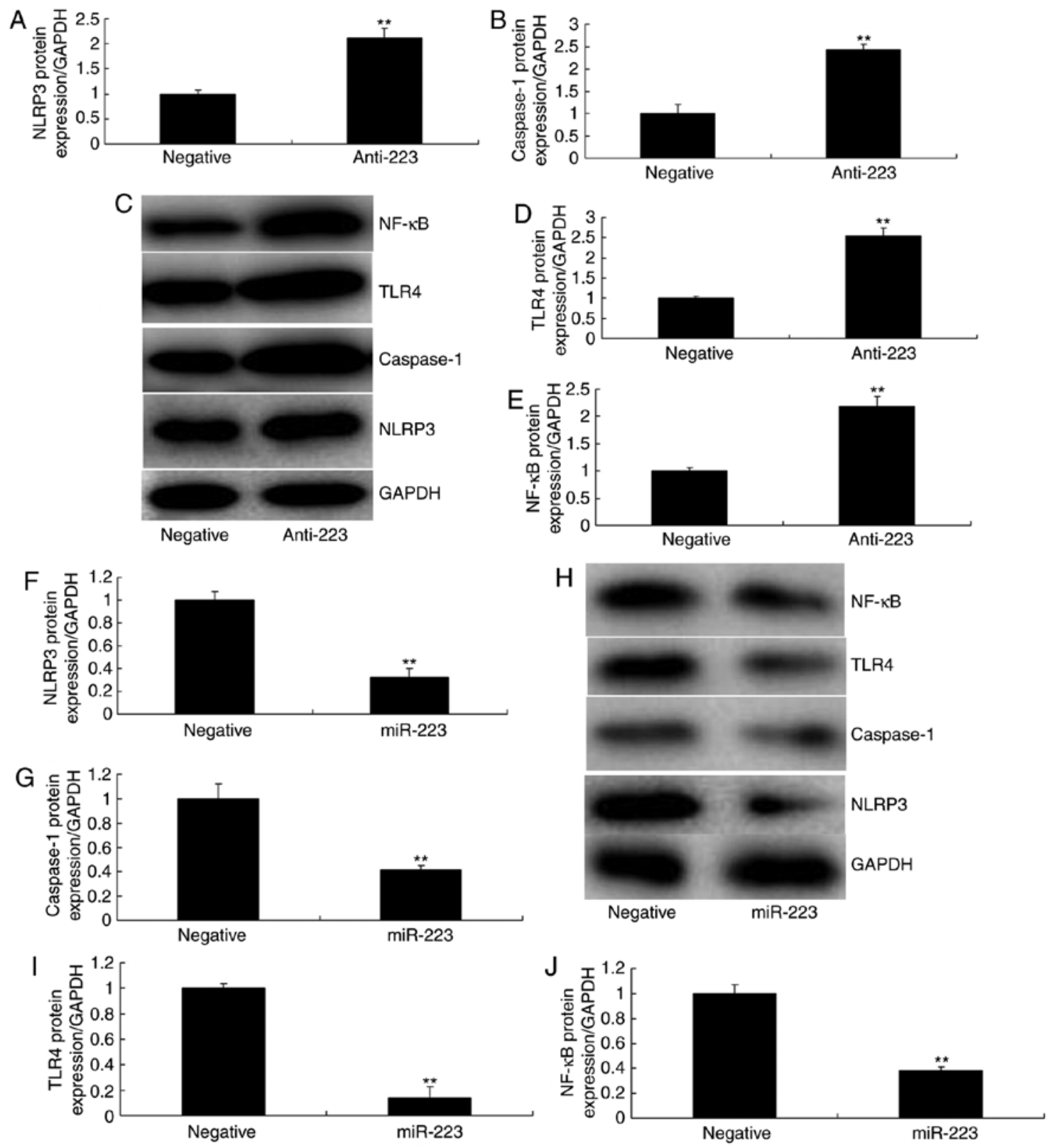

Figure 4. miR-223 regulates the TLR4 and NLRP3 signaling pathway in acute lung injury in vitro. (A) NLRP3 and (B) caspase-1 protein expression was quanti-

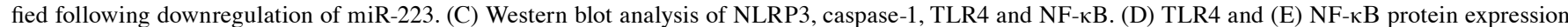
was quantified following downregulation of miR-223. (F) NLRP3 and (G) caspase-1 protein expression was quantified following upregulation of miR-223.

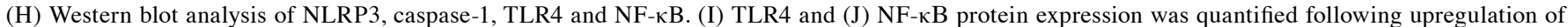
miR-223. ${ }^{* *} \mathrm{P}<0.01$ vs. negative control. NLRP3, NACHT, LRR and PYD domains-containing protein 3; miR, microRNA; TLR4, toll-like receptor 4; NF- $\mathrm{BB}$, nuclear factor- $\mathrm{kB}$.

the protein expression of TLR4, NF- $\mathrm{KB}, \mathrm{NLRP} 3$ and caspase-1 in ALI in vitro, compared with the negative control group (Fig. 4A-E). Overexpression of miR-223 suppressed the protein expression of TLR4, NF- $\mathrm{B}$, NLRP3 and caspase-1 in ALI in vitro, compared with the negative control group (Fig. 4F-J). Taken together, these results demonstrated that miR-223 may regulate the TLR4 and NLRP3 signaling pathway in ALI in vitro.

Inhibition of TLR4 reduces the pro-inflammatory effect of anti-miR-223 in ALI in vitro. To elucidate the mechanism of action of miR-223 in ALI in vitro, a TLR4 inhibitor was used to decrease the protein expression of TLR4 in ALI in vitro. The inhibition of TLR4 did not affect the protein expression of NLRP3 and caspase-1, but suppressed that of TLR4 and NF- $\mathrm{BB}$ in ALI in vitro following miR-223 downregulation, compared with miR-223 downregulation alone (Fig. 5A-E). The inhibition of TLR4 reduced the levels of IL-1 $\beta$ and IL-18 in ALI in vitro following miR-223 downregulation, in comparison with miR-223 downregulation alone (Fig. 5F and G). Taken together, these results demonstrated that TLR4 is required to maintain the proinflammatory effect of anti-miR-223 in ALI.

Inhibition of NLRP3 reduces the pro-inflammatory effect of anti-miR-223 in ALI in vitro. To further elucidate the role 

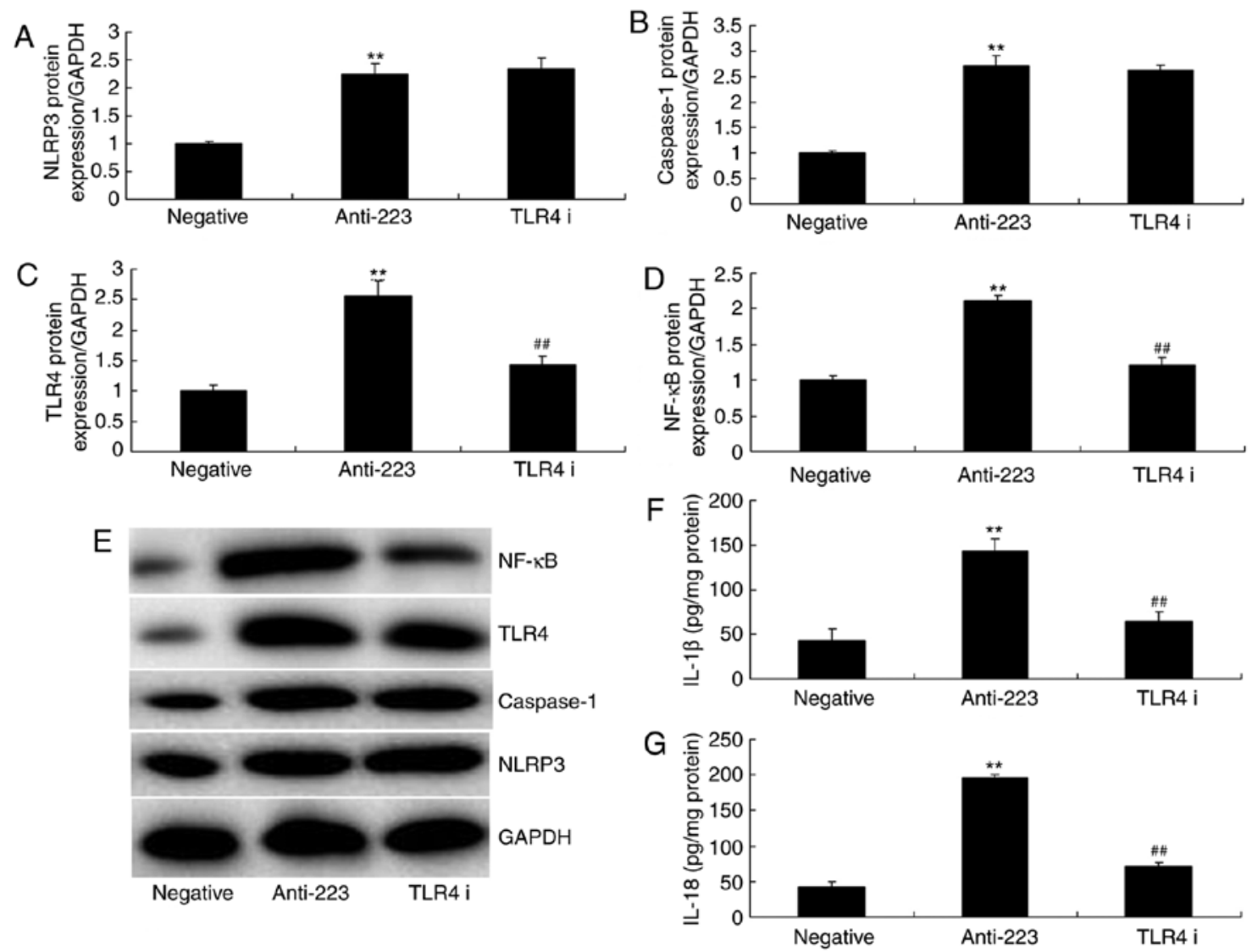

Figure 5. Inhibition of TLR4 reduces the pro-inflammatory effect of anti-miR-223 on inflammation in acute lung injury in vitro. (A) NLRP3, (B) caspase-1,

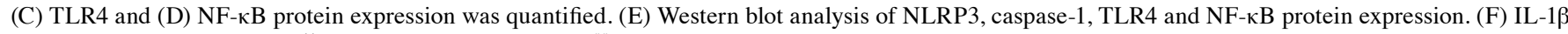
and (G) IL-18 were analyzed. ${ }^{* *} \mathrm{P}<0.01$ vs. negative control; ${ }^{\# \#} \mathrm{P}<0.01$ vs. anti-223 group. TLR4 $\mathrm{i}$, TLR4 inhibitor and anti-miR-233 combined; NLRP3, NACHT,

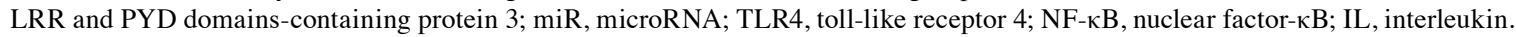
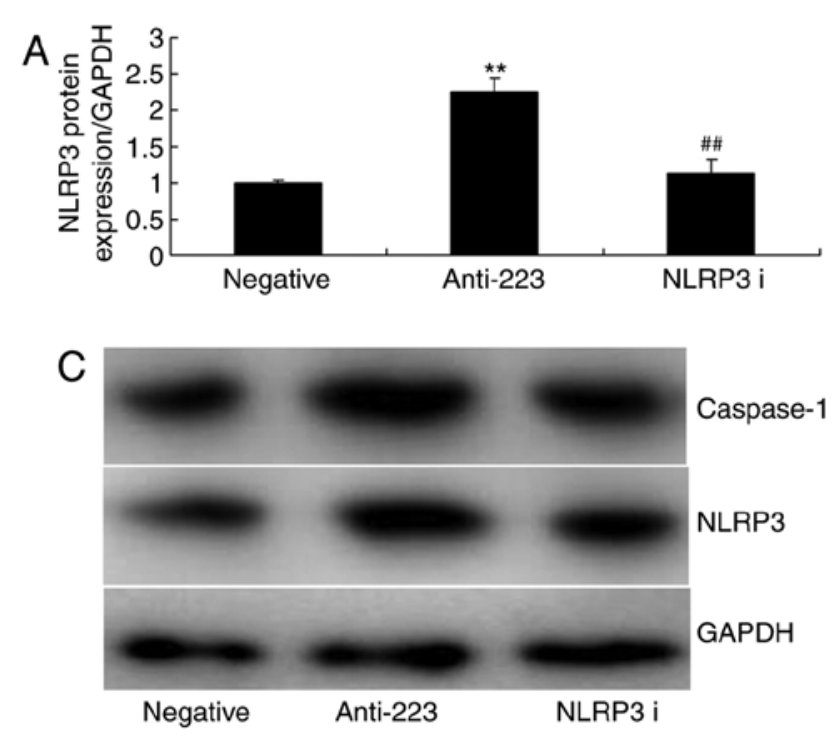
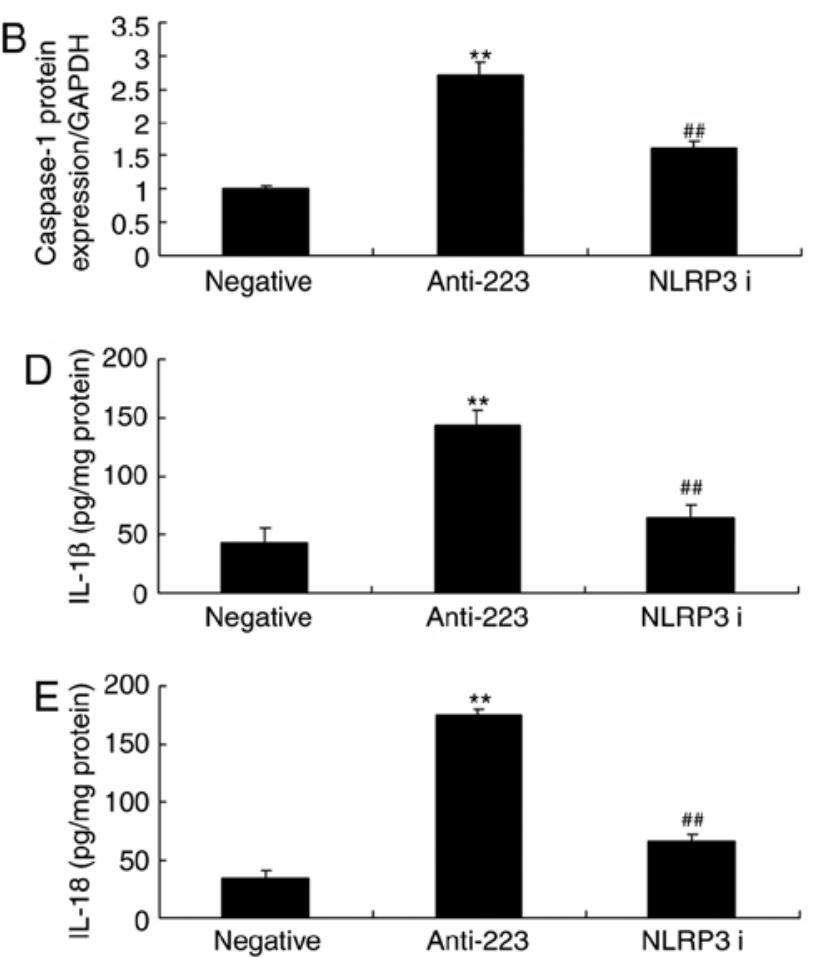

Figure 6. Inhibition of NLRP3 reduces the pro-inflammatory effect of anti-miR-223 on inflammation in acute lung injury in vitro. (A) NLRP3 and (B) caspase-1 protein expression was quantified. (C) Western blot analysis of NLRP3 and caspase-1 protein expression. (D) IL-1 $\beta$ and (E) IL-18 were analyzed. ${ }^{* *} \mathrm{P}<0.01$ vs. negative control; ${ }^{\# \#} \mathrm{P}<0.01$ vs. anti-223 group. NLRP3, NACHT, LRR and PYD domains-containing protein 3; NLRP3 i, NLRP3 inhibitor and anti-miR-233 combined; miR, microRNA; IL, interleukin. 

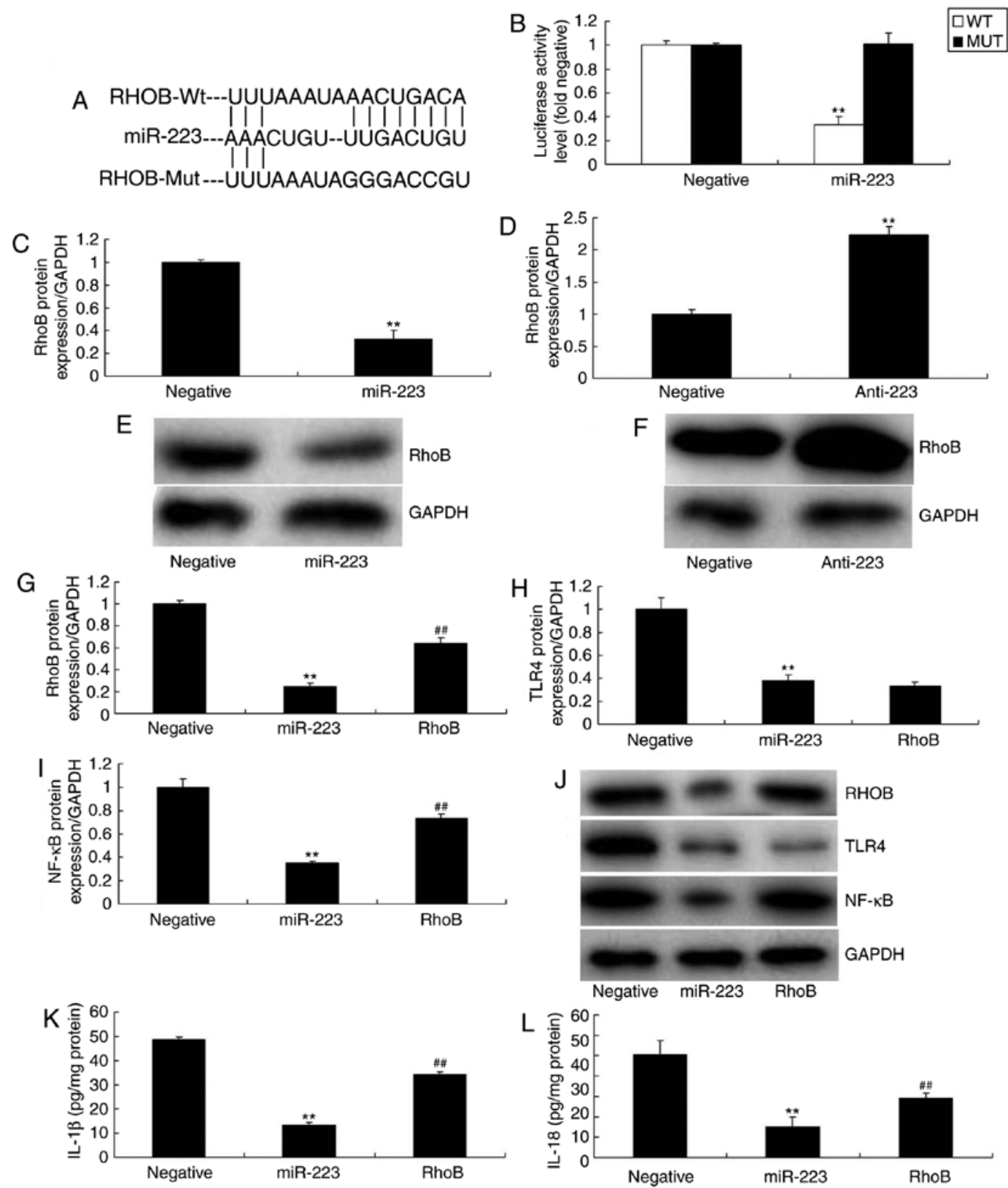

Figure 7. miR-223 regulates the TLR4 signaling pathway in acute lung injury in vitro via RHOB. (A) Predicted miR-223 binding sites in the RHOB 3'-untranslated region. (B) Dual-luciferase reporter gene assay. RHOB protein expression was quantified in cells with (C) miR-223 upregulation and (D) miR-223 downregulation. Western blot analysis of RHOB protein expression in cells with (E) miR-223 upregulation and (F) miR-223 downregulation. (G) RHOB,

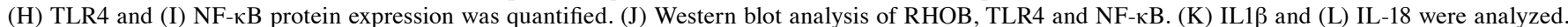
${ }^{* *} \mathrm{P}<0.01$ vs. negative control; ${ }^{\# \#} \mathrm{P}<0.01$ vs. miR-223 group. RHOB, rho-related GTP-binding protein RhoB; miR, microRNA; TLR4, toll-like receptor 4; NF-kB, nuclear factor- $\kappa \mathrm{B}$; IL, interleukin.

of NLRP3 in the pro-inflammatory effect of anti-miR-223 in ALI in vitro, an NLRP3 inhibitor was used to decrease the protein expression of NLRP3. As a result, the inhibition of NLRP3 suppressed the protein expression of NLRP3 and caspase-1 in ALI in vitro following treatment with anti-miR-223, compared with treatment with anti-miR-223 alone (Fig. 6A-C). The inhibition of NLRP3 reduced the levels of IL-1 $\beta$ and IL-18 in ALI in vitro following treatment with anti-miR-223, compared with treatment with anti-miR-223 alone (Fig. 6D and E). Taken together, these results demonstrated that NLRP3 is required to maintain the proinflammatory effect of anti-miR-223 in ALI, mediated by IL-1 $\beta$ and IL-18.
miRNA-223 regulates the TLR4 signaling pathway in ALI in vitro via $R H O B$. Prior to determining the role of miR-223 in RHOB-activated inflammation, the 3'-UTR of RHOB mRNA was revealed to be a target site of miR-223 in various species (Fig. 7A). The relative luciferase activity of the wild-type 3'UTR in miR-223 was decreased compared with the control group (Fig. 7B). Overexpression of miR-223 suppressed the protein expression of RHOB, while downregulation of miR-223 induced RHOB protein expression in ALI in vitro, compared with the negative control group (Fig. 7C-F). A RHOB plasmid was utilized to induce the protein expression of RHOB, which did not affect TLR4 protein expression in ALI in vitro following treatment with anti-miR-223, compared 

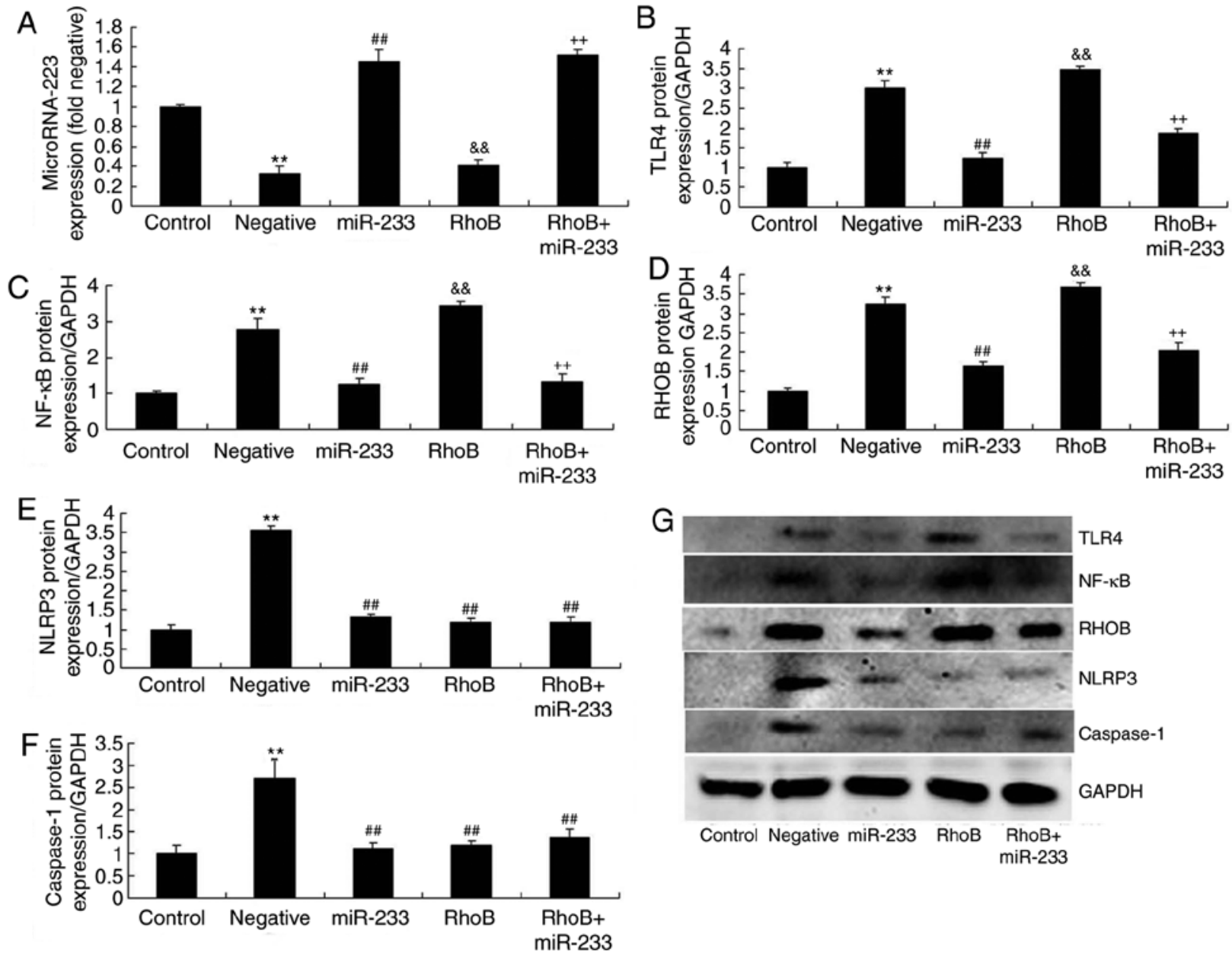

Figure 8. Activation of RHOB reduces the effects of miR-223 on inflammation in acute lung injury in vitro. (A) miR-223, (B) TLR4, (C) NF- $\kappa \mathrm{B}$, (D) RHOB, (E) NLRP3 and (F) caspase-1 protein expression was quantified. (G) Western blot analysis. ${ }^{* *} \mathrm{P}<0.01$ vs. control group; ${ }^{\# \prime} \mathrm{P}<0.01 \mathrm{vs}$. negative control; \&\&P<0.01 vs. miR-223 group; ${ }^{++} \mathrm{P}<0.01$ vs. RhoB group. miR, microRNA; RHOB, rho-related GTP-binding protein RhoB, rho-related GTP-binding protein RhoB; TLR4, toll-like receptor 4; NF- $\kappa$ B, nuclear factor- $\kappa \mathrm{B}$; NLRP3, NACHT, LRR and PYD domains-containing protein 3.

with treatment with anti-miR-223 alone (Fig. 7G-I). The activation of RHOB reduced the pro-inflammatory effect of anti-miR-223 on the levels of IL-1 $\beta$ and IL-18 in ALI in vitro following treatment with anti-miR-223, compared with treatment with anti-miR-223 alone (Fig. 7J and K).

Activation of RHOB reduces the effects of miR-223 on inflammation in ALI in vitro. To further study the role of RHOB in the effects of miR-223 on inflammation in ALI in vitro, $\mathrm{RHOB}$ plasmid was used to induce RHOB protein expression in ALI following overexpression of miR-223. RHOB plasmid did not affect miR-223 expression in the ALI model, compared with the negative group (Fig. 8A). As presented in Fig. 8B-G, RHOB plasmid induced RHOB, TLR4 and NF- $\kappa \mathrm{B}$ protein expression, and did not affect NLRP3 and caspase-1 protein expression in ALI following overexpression of miR-223, compared with overexpression of miR-223 alone.

\section{Discussion}

ALI/ARDS is a common and important rapidly progressive inflammatory lung disease. It is estimated that there are 190,000 new ALI cases in the USA annually, with approxi-

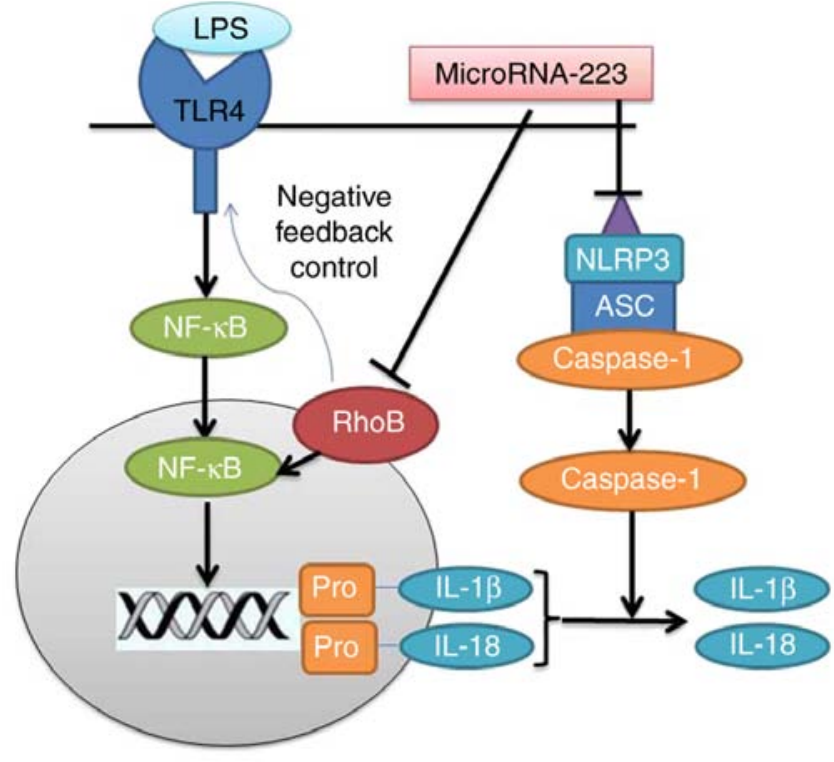

Figure 9. MicroRNA-223 attenuates LPS-induced inflammation in acute lung injury model via the NLRP3 inflammasome. LPS, lipopolysaccharide; RHOB, rho-related GTP-binding protein RhoB; TLR4, Toll-like receptor 4; NF- $\kappa \mathrm{B}$, nuclear factor- $\kappa \mathrm{B}$; NLRP3, NACHT, LRR and PYD domains-containing protein 3; IL, interleukin; ASC, PYD and CARD domain containing. 
mately 75,000 mortalities (2). In China, the incidence of ALI/ARDS is even higher, with a mortality rate of 52\% (14). In recent years, scientists have noticed that miRNAs serve vital roles in multiple biological processes and signal transduction pathways of ALI/ARDS (14). In the present study, it was identified that miRNA-223 expression was decreased in ALI mice. Neudecker et al (12) suggested that miRNA-223 deficiency was associated with severe lung inflammation.

ALI/ARDS is damage to alveolar epithelial cells and capillary endothelial cells due to a variety of direct causes (including pneumonia and pulmonary contusion) and indirect causes (including adenosis and trauma) (15). This leads to diffuse edema of the pulmonary interstitium and alveoli, subsequently triggering acute hypoxemia. ALI/ARDS is not considered a simple lung disease or inflammatory disease $(15,16)$. Instead, it is a systemic inflammatory response in the lung tissue, according to current opinion (17). In cases of ALI/ARDS, neutrophils, macrophages and endothelial cells release a large quantity of proinflammatory cytokines, chemokines and inflammatory mediators. This leads to damage to the lung epithelial cells and pulmonary vascular endothelial cells, increased alveolar permeability, and exudation of inflammatory cells, proteins and water. Additionally, this results in reduced lung tissue volume, decreased pulmonary compliance, disorders of gas diffusion, exchange and metabolism, and eventual mortality attributed to respiratory failure. The present study demonstrated that the downregulation of miRNA-223 promoted IL-1 $\beta$ and IL-18 levels in A549 cells treated with LPS, and the downregulation of miRNA-223 promoted TLR4 and NF- $\kappa \mathrm{B}$ protein expression in A549 cells treated with LPS. Wang et al (18) indicated that miRNA-223 negatively regulated the activation of the TLR4/NF- $\kappa \mathrm{B}$ pathway in macrophages.

In the occurrence and development of ALI, the release of proinflammatory mediators and apoptosis serve an important role (19). Disorders of the secretion of cytokines, inflammatory chemokines and other associated proteins promote the inflammatory response and accelerate the development of lung injury (20). Previous studies have confirmed that the NLRP3 inflammasome serves an important role in this process $(21,22)$. It not only activates caspase- 1 and inflammatory factors, but also promotes the maturation and secretion of inflammasomes $(21,22)$. Therefore, the regulatory approach targeting NLRP3 inflammasomes may be of great importance for the treatment of ALI. The NLRP3 inflammasome is a multiprotein large-cytoplasmic complex that is composed of NLRP3, apoptosis-related spot-like proteins and pro-caspase-1 (23). NLRP3 serves a critical role in regulating the relevant components of the inflammation complex, including apoptosis-related point-like proteins and pro-caspase-1 (23). Recent studies have confirmed that activation of the inflammasome induces the division of pro-IL-1B and pro-IL-18 $(21,22)$. Furthermore, it results in increased alveolar permeability, subsequently leading to pulmonary edema and lung injury $(21,22)$. In the present study, miRNA-223 negatively regulated the TLR4/ $\mathrm{NF}-\kappa \mathrm{B}$ signaling pathway via RHOB in ALI. Downregulation of miRNA-223 induced TLR4, NF- $\mathrm{B}$, NLRP3 and caspase-1 protein expression in ALI in vitro. Yang et al (24) reported that miRNA-223 regulates inflammation and brain injury via feedback to NLRP3 inflammasome after intracerebral hemor- rhage. Zeng et al (25) demonstrated that miRNA-223 attenuates hypoxia-induced vascular remodeling through $\mathrm{RHOB} /$ myosin light chain 9 in pulmonary arterial smooth muscle.

In conclusion, the present study demonstrated that miRNA-223 reduced inflammation, suppressed the NLRP3 inflammasome, and negatively regulated the TLR4/NF- $\kappa \mathrm{B}$ signaling pathway via RHOB in ALI (Fig. 9). miRNA-223 is involved in the activation of the TLR4/NF- $\kappa \mathrm{B}$ signaling pathway via RHOB, and the NLRP3 inflammasome may be a therapeutic target for the treatment of inflammation in ALI. Therefore, miRNA-223 serves as a potent positive regulator of inflammation in ALI.

\section{Acknowledgements}

Not applicable.

\section{Funding}

No funding was received.

\section{Availability of data and materials}

The analyzed data sets generated during the study are available from the corresponding author on reasonable request.

\section{Authors' contributions}

ZZ designed the study. YY, KL and TY performed the experiments. ZZ and YY analyzed the data. ZZ wrote the manuscript.

\section{Ethics approval and consent to participate}

The experimental procedures in the present study were performed with the approval of Binzhou Medical University Hospital (Binzhou, China).

\section{Patient consent for publication}

Not applicable.

\section{Competing interests}

The authors declare that they have no competing interests.

\section{References}

1. Cheng Y, Jin M, Dong X, Sun L, Liu J, Wang R, Yang Y, Lin P, Hou S, Ma Y, et al: Mechanism and early intervention research on ALI during emergence surgery of stanford type-A AAD: Study protocol for a prospective, double-blind, clinical trial. Medicine (Baltimore) 95: e5164, 2016.

2. Zhang J, Cao J, Feng J, Wu Q and Chen BY: A study of noninvasive positive-pressure mechanical ventilation in the treatment of acute lung injury with a complex critical care ventilator. J Int Med Res 42: 788-798, 2014.

3. Meade MO, Cook DJ, Griffith LE, Hand LE, Lapinsky SE, Stewart TE, Killian KJ, Slutsky AS and Guyatt GH: A study of the physiologic responses to a lung recruitment maneuver in acute lung injury and acute respiratory distress syndrome. Respir Care 53: 1441-1449, 2008.

4. Guo H, Suo DW, Zhu HP, Sun XM and Chen J: Early blood purification therapy of severe acute pancreatitis complicated by acute lung injury. Eur Rev Med Pharmacol Sci 20: 873-878, 2016. 
5. Tian L, Li W and Wang T: Therapeutic effects of silibinin on LPS-induced acute lung injury by inhibiting NLRP3 and NF- $\kappa$ B signaling pathways. Microb Pathog 108: 104-108, 2017.

6. Zhang A, Pan W, Lv J and Wu H: Protective effect of amygdalin on LPS-induced acute lung injury by inhibiting NF- $\kappa \mathrm{B}$ and NLRP3 signaling pathways. Inflammation 40: 745-751, 2017.

7. Fukumoto J, Fukumoto I, Parthasarathy PT, Cox R, Huynh B, Ramanathan GK, Venugopal RB, Allen-Gipson DS, Lockey RF and Kolliputi N: NLRP3 deletion protects from hyperoxia-induced acute lung injury. Am J Physiol Cell Physiol 305: C182-C189, 2013.

8. Zhang Y, Li X, Grailer JJ, Wang N, Wang M, Yao J, Zhong R, Gao GF, Ward PA, Tan DX and Li X: Melatonin alleviates acute lung injury through inhibiting the NLRP3 inflammasome. J Pineal Res 60: 405-414, 2016.

9. Cao Y, Lyu YI, Tang J and Li Y: MicroRNAs: Novel regulatory molecules in acute lung injury/acute respiratory distress syndrome. Biomed Rep 4: 523-527, 2016.

10. Rajasekaran S, Pattarayan D, Rajaguru P, Sudhakar Gandhi PS and Thimmulappa RK: MicroRNA regulation of acute lung injury and acute respiratory distress syndrome. J Cell Physiol 231: 2097-2106, 2016

11. Neudecker V, Yuan X, Bowser JL and Eltzschig HK: MicroRNAs in mucosal inflammation. J Mol Med (Berl) 95: 935-949, 2017.

12. Neudecker V, Brodsky KS, Clambey ET, Schmidt EP, Packard TA, Davenport B, Standiford TJ, Weng T, Fletcher AA, Barthel L, et al: Neutrophil transfer of miR-223 to lung epithelial cells dampens acute lung injury in mice. Sci Transl Med 9: eaah5360, 2017.

13. Livak KJ and Schmittgen TD: Analysis of relative gene expression data using real-time quantitative PCR and the 2(-Delta Delta C(T)) method. Methods 25: 402-408, 2001.

14. Bechir M, Puhan MA, Fasshauer M, Schuepbach RA, Stocker R and Neff TA: Early fluid resuscitation with hydroxyethyl starch 130/0.4 (6\%) in severe burn injury: A randomized, controlled, double-blind clinical trial. Crit Care 17: R299, 2013.

15. Barr LC, Brittan M, Morris AC, McAuley DF, McCormack C, Fletcher AM, Richardson H, Connell M, Patel D, Wallace WA, et al: A randomized controlled trial of peripheral blood mononuclear cell depletion in experimental human lung inflammation. Am J Respir Crit Care Med 188: 449-455, 2013.

16. Aikawa N, Ishizaka A, Hirasawa H, Shimazaki S, Yamamoto Y, Sugimoto H, Shinozaki M, Taenaka N, Endo S, Ikeda T and Kawasaki Y: Reevaluation of the efficacy and safety of the neutrophil elastase inhibitor, sivelestat, for the treatment of acute lung injury associated with systemic inflammatory response syndrome; a phase IV study. Pulm Pharmacol Ther 24: 549-554, 2011
17. Krupa A, Fol M, Rahman M, Stokes KY, Florence JM, Leskov IL, Khoretonenko MV, Matthay MA, Liu KD, Calfee CS, et al: Silencing Bruton's tyrosine kinase in alveolar neutrophils protects mice from LPS/immune complex-induced acute lung injury. Am J Physiol Lung Cell Mol Physiol 307: L435-L448, 2014.

18. Wang J, Bai X, Song Q, Fan F, Hu Z, Cheng G and Zhang Y: miR-223 inhibits lipid deposition and inflammation by suppressing toll-like receptor 4 signaling in macrophages. Int $\mathbf{J}$ Mol Sci 16: 24965-24982, 2015.

19. Feng Z, Qi S, Zhang Y, Qi Z, Yan L, Zhou J, He F, Li Q, Yang Y, Chen Q, et al: Ly6G+ neutrophil-derived miR-223 inhibits the NLRP3 inflammasome in mitochondrial DAMP-induced acute lung injury. Cell Death Dis 8: e3170, 2017.

20. Jiang L, Fei D, Gong R, Yang W, Yu W, Pan S, Zhao M and Zhao M: CORM-2 inhibits TXNIP/NLRP3 inflammasome pathway in LPS-induced acute lung injury. Inflamm Res 65: 905-915, 2016.

21. Xiang M, Shi X, Li Y, Xu J, Yin L, Xiao G, Scott MJ, Billiar TR, Wilson MA and Fan J: Hemorrhagic shock activation of NLRP3 inflammasome in lung endothelial cells. J Immunol 187: 4809-4817, 2011.

22. Jiang W, Li M, He F, Bian Z, Liu J, He Q, Wang X, Sun T and Zhu L: Dopamine D1 receptor agonist A-68930 inhibits NLRP3 inflammasome activation and protects rats from spinal cord injury-induced acute lung injury. Spinal Cord 54: 951-956, 2016.

23. Jiang L, Zhang L, Kang K, Fei D, Gong R, Cao Y, Pan S, Zhao M and Zhao M: Resveratrol ameliorates LPS-induced acute lung injury via NLRP3 inflammasome modulation. Biomed Pharmacother 84: 130-138, 2016.

24. Yang Z, Zhong L, Xian R and Yuan B: MicroRNA-223 regulates inflammation and brain injury via feedback to NLRP3 inflammasome after intracerebral hemorrhage. Mol Immunol 65: 267-276, 2015.

25. Zeng Y, Zhang X, Kang K, Chen J, Wu Z, Huang J, Lu W, Chen Y, Zhang J, Wang Z, et al: MicroRNA-223 attenuates hypoxia-induced vascular remodeling by targeting rhoB/MLC2 in pulmonary arterial smooth muscle cells. Sci Rep 6: 24900, 2016.

This work is licensed under a Creative Commons Attribution-NonCommercial-NoDerivatives 4.0 International (CC BY-NC-ND 4.0) License. 